\title{
MICROSTRUCTURAL ANALYSIS ON 3D PRINTED NICKEL-BASED ALLOY 718
}

\author{
Naing Naing Aung, Ting Chen, Jairus Morton, Xingbo Liu \\ Mechanical and Aerospace Engineering Department, West Virginia University, \\ Morgantown, WV 26506, USA
}

Keywords: 3D printing, nickel-based alloy 718 , heat treatment, microstructure, microhardness

\begin{abstract}
$3 \mathrm{D}$ printing is a rapidly growing technology for the fabrication of nickel-based alloy products in the aerospace industry because of its time efficiency, relative affordability, ease of use and design freedom. The alloy was initially built by selective laser melting technique, followed by stress relieving, hot isostatic pressing, and heat treatment processes. How process parameters affect the microstructure of $3 \mathrm{D}$ printed alloy 718 , however, is not well understood. In this research, the grain size changes and the microstructural evolution of as-built samples were studied under different heat treatment conditions. The HT-1 treatment (solution treatment at $950{ }^{\circ} \mathrm{C} / 1 \mathrm{~h} / \mathrm{water}$ quenching followed by two-stage ageing at $720{ }^{\circ} \mathrm{C} / 8 \mathrm{~h} /$ furnace cooling to $620{ }^{\circ} \mathrm{C} / 8 \mathrm{~h} /$ air cooling to room temperature) reduced the grain size of aged microstructure twice compared with the standard AMS 5662 (solution treatment at $980{ }^{\circ} \mathrm{C} / 1 \mathrm{~h} /$ water quenching followed by two-stage ageing at $720{ }^{\circ} \mathrm{C} / 8 \mathrm{~h} /$ furnace cooling to $620^{\circ} \mathrm{C} / 8 \mathrm{~h} /$ air cooling to room temperature) due to the existence of acicular grain boundary $\delta$ phase. However, the high volume fraction of $\gamma^{\prime} / \gamma^{\prime \prime}$ precipitates in the HT-2 (solution treatment at $1035^{\circ} \mathrm{C} / 1 \mathrm{~h} /$ water quenching followed by twostage ageing at $720{ }^{\circ} \mathrm{C} / 10 \mathrm{~h} /$ furnace cooling to $620{ }^{\circ} \mathrm{C} / 10 \mathrm{~h} /$ air cooling to room temperature) aged microstructure led to increase the microhardness value.
\end{abstract}

\section{Introduction}

With the rapid development of modern industry, nickel-based alloy 718 parts with complex structures, high dimension precision and further elevated mechanical and corrosion properties are in higher demand $[1,2]$. Thus, the application of 3D printing process is currently being utilized by several industries, including the automotive and aerospace industries. This process has been recognized as a promising additive manufacturing technology because it offers near net shape production of alloy parts with complex configurations and high performance within hours [3-5].

3D printed alloy 718 is manufactured through selective laser melting. Stress relieving, hot isostatic pressing, and solution plus ageing heat treatment processes are subsequently conducted to the as-built structure. These different steps of 3D printing process affect the microstructure of the alloy. It has been suggested that the standard AMS 5662 heat treatment recommended for wrought IN 718 is not appropriate for the direct HIP processed ones. This heat treatment results in the precipitation of carbide and $\delta$ phase as well as the formation of thermal induced pores which lead to the decrease of grain boundary strength $[6,7]$. The direct ageing heat treatment ensures a good balance of the strength and ductility. However, owing to over ageing of the precipitates, its yield strength is lower than that of the solution treated conditions [7]. 
To optimize the mechanical as well as corrosion properties of the alloy it is essential to characterize and quantify the grain size as well as the volume fractions of the precipitation phases (the carbides, $\delta\left(\mathrm{Ni}_{3} \mathrm{Nb}\right), \gamma^{\prime}\left(\mathrm{Ni}_{3}(\mathrm{Al}, \mathrm{Ti})\right)$ and $\left.\gamma^{\prime \prime}\left(\mathrm{Ni}_{3} \mathrm{Nb}\right)\right)$. The fine grain structure is essential for improved tensile and fatigue properties. On the other hand, the coarse grain structure is required for lower tensile strength combined with enhanced creep resistance. Hardening by the precipitation of $\gamma^{\prime \prime}$ is considered to be primarily responsible for the strengthening in the alloy 718 [8]. The effect of grain size and precipitation phases could play an important role in its corrosion behavior. Significant research efforts are still required to find an appropriate heat treatment to improve the structure and properties of $3 \mathrm{D}$ printed alloy 718 . In the present work, special attention paid to study the relationship between heat treatment processes and the microstructural changes.

\section{Materials and Experiments}

The alloy 718 samples were built by selective laser melting process with EOS M270 machine. Comparison of composition before and after processing showed the selective laser melting process did not change the initial powder chemistry (not shown), and the composition meets the AMS 5662 requirement. The samples/coupons were heat treated with solution treatment and two-stage ageing treatment (HT) after stress relieving (SR) and hot isostatic pressing (HIP). In this work, two different heat treated conditions (HT-1 and HT-2) were conducted to study the evolution of aged microstructures to compare with AMS 5662. Detailed information about HT process parameters is listed in Table I. The microstructures of the samples were characterized using optical microscopy (OM) and scanning electron microscopy (SEM). Samples for OM and SEM observations were manually ground, polished and chemically etched. The distribution of precipitates in the aged microstructures was identified by X-ray diffraction (XRD). To relate microstructure evolution to mechanical properties of different aged samples, Vickers hardness measurements were carried out at least at five locations on each sample.

Table I. Experimental conditions for different heat treatments

\begin{tabular}{|c|c|c|c|}
\hline Treatment & Temperature & Time & Cooling condition \\
\hline \multicolumn{4}{|c|}{ AMS 5662} \\
\hline Solid solution & $980^{\circ} \mathrm{C}$ & $1 \mathrm{~h}$ in Argon & Water quench \\
\hline Precipitation & $\begin{array}{l}720^{\circ} \mathrm{C} \\
620^{\circ} \mathrm{C}\end{array}$ & $\begin{array}{c}8 \mathrm{~h} \text { in Argon } \\
\text { Hold at } 620^{\circ} \mathrm{C} \text { for } 8 \mathrm{~h}\end{array}$ & $\begin{array}{c}38^{\circ} \mathrm{C} / \mathrm{h} \text { to } 620^{\circ} \mathrm{C} \\
\text { Air cool }\end{array}$ \\
\hline \multicolumn{4}{|c|}{ HT-1 } \\
\hline Solid solution & $950^{\circ} \mathrm{C}$ & $1 \mathrm{~h}$ in Argon & Water quench \\
\hline Precipitation & $\begin{array}{l}720^{\circ} \mathrm{C} \\
620^{\circ} \mathrm{C} \\
\end{array}$ & $\begin{array}{c}8 \mathrm{~h} \text { in Argon } \\
\text { Hold at } 620^{\circ} \mathrm{C} \text { for } 8 \mathrm{~h}\end{array}$ & $\begin{array}{c}38^{\circ} \mathrm{C} / \mathrm{h} \text { to } 620^{\circ} \mathrm{C} \\
\text { Air cool }\end{array}$ \\
\hline \multicolumn{4}{|c|}{ HT-2 } \\
\hline Solid solution & $1035^{\circ} \mathrm{C}$ & $1 \mathrm{~h}$ in Argon & Water quench \\
\hline Precipitation & $\begin{array}{l}720^{\circ} \mathrm{C} \\
620^{\circ} \mathrm{C} \\
\end{array}$ & $\begin{array}{l}10 \mathrm{~h} \text { in Argon } \\
\text { Hold at } 620^{\circ} \mathrm{C} \text { for } 10 \mathrm{~h}\end{array}$ & $\begin{array}{c}55^{\circ} \mathrm{C} / \mathrm{h} \text { to } 620^{\circ} \mathrm{C} \\
\text { Air cool }\end{array}$ \\
\hline
\end{tabular}




\section{Results and Discussions}

\section{Microstructures after Stress Relieving and HIP}

Due to the rapid solidification of the molten pool during laser melting, the microstructure of asbuilt sample contained the columnar grains which grow epitaxially along the deposition direction from the substrate (Figure 1a). These columnar grains can be substituted by heat treated equiaxed grains via stress relieving treatment. The SR-1 treatment $\left(960{ }^{\circ} \mathrm{C}\right.$ for $\left.3 \mathrm{~h}\right)$ did not result in complete recrystallization (Figure $1 \mathrm{~b}$ ). However, the grain boundaries become obvious after the SR-2 treatment $\left(1038^{\circ} \mathrm{C}\right.$ for $1 \mathrm{~h}$ ) (Figure 1c), which resulted from the enhancement of solute diffusion at a higher temperature. Normally, the SR treatment is carried out at $1066^{\circ} \mathrm{C}$ for $1.5 \mathrm{~h}$ to ensure complete recrystallization. The recrystallization driving force is attributed to the residual thermal stress accumulated during the repeated rapid heating and cooling process during to some extent [9]. However, the average grain size after recrystallization is large $(>100 \mu \mathrm{m})$ compared with the wrought alloy 718 which has an average grain diameter of about $24 \mu \mathrm{m}$ because the residual thermal strain is not as great as the strain caused by traditional mechanical deformation treatment [9].

The internal porosity of the stress relieved samples were removed by HIP. It combines higher pressure and temperature to produce materials and parts with substantially better properties than those by other methods $[10,11]$. The similar microstructures were observed after HIP treatment of SR-1 and SR-2 samples (Figures 1d and 1e).

\section{Aged Microstructures after Different Heat Treatment Conditions}

The samples after SR and HIP treatments were given the solid solution and two-stage ageing treatment as per the schedule in Table I. Figure 2 shows the typical aged microstructures of three different heat treatments. It is obvious that the grain size of the microstructures were different from each other. The average grain size of the SR+HIP+AMS 5662 aged microstructure was 100 $\mu \mathrm{m}$ (Figure 2a) which is slightly larger than that of the SR-2+HIP+HT-2 aged microstructure (Figure 2c). In contrast, the HT-1 treatment gave the smallest average grain size of $50 \mu \mathrm{m}$ (Figure 2b). The solid solution treatment of alloy 718 is normally carried out at $980{ }^{\circ} \mathrm{C}$, slightly below $\delta$ solvus $\left(995{ }^{\circ} \mathrm{C}\right)$, to have sufficient amount of $\delta$ phase for grain size control and inhibiting grain growth through pinning of grain boundaries by $\delta$. The results suggest that the solution treatment at $950{ }^{\circ} \mathrm{C}$ (HT-1) showed significant effects on the reduction of grain size The treatments at $980{ }^{\circ} \mathrm{C}$ (AMS 5662) and $1035{ }^{\circ} \mathrm{C}$ (HT-2) were enough to induce grain coarsening.

The effect of HT-1 and HT-2 on phase precipitation behavior was investigated by XRD analysis in compared with the AMS 5662 heat treatment (Figure 3). XRD analysis reveals that the $\delta$ phase existed in the SR-1+HIP and SR-2+HIP microstructures. The low volume fraction of $\delta$ phase appears during the HIP treatment and it gradually dissolves as the temperature and pressure increase of the HIP treatment [12]. The $\delta$ and $\gamma^{\prime} / \gamma^{\prime \prime}$ phases precipitated out during the two-stage aging heat treatment, but the peaks of the $\delta$ phase in the SR-1+HIP + HT- 1 aged microstructure was the most significant. Its most intense peak was observed at $46.11^{\circ}$ and this $2 \theta$ value is consistent with the experimental results from other research [13]. The $\gamma^{\prime}$ usually forms at a higher temperature of ageing $\left(720^{\circ} \mathrm{C}\right)$ while the precipitation of $\gamma^{\prime \prime}$ takes place at the lower temperature of ageing $\left(620^{\circ} \mathrm{C}\right)$. Both phases are metastable and at higher temperature usually more than $650^{\circ} \mathrm{C}$ the $\gamma^{\prime \prime}$ coarsens very fast and transforms into either $\gamma^{\prime}$ or orthorhombic $\delta$ [8, 13]. The high intensities of $\mathrm{NbC}$ peaks were detected in the SR-2+HIP+HT-2 aged microstructure (Figure 3 ). 


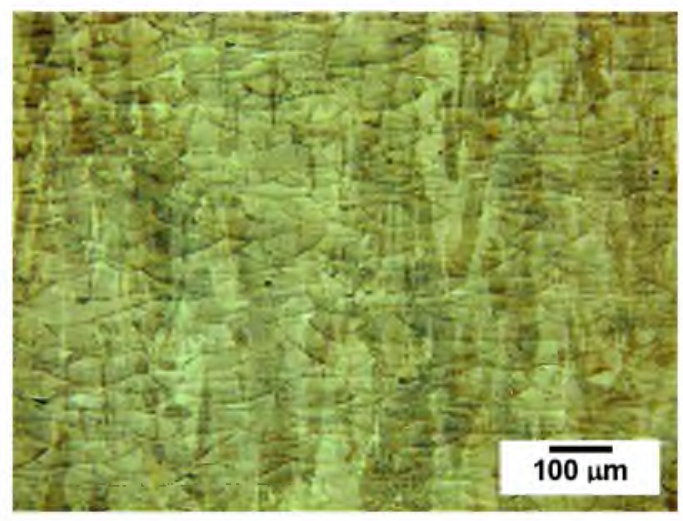

(a)

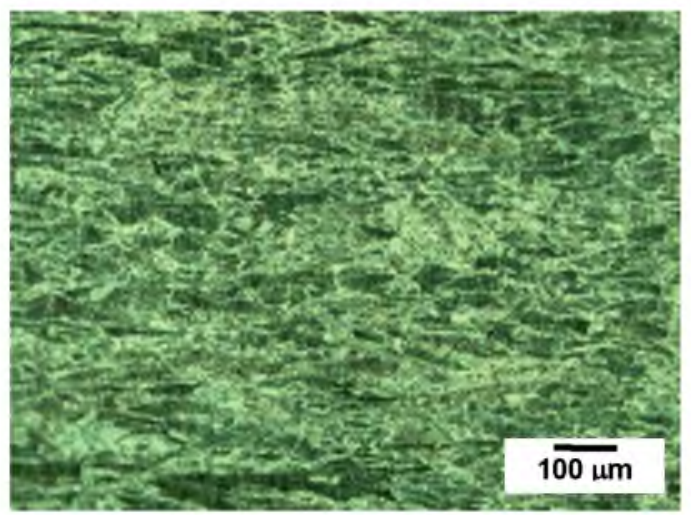

(b)

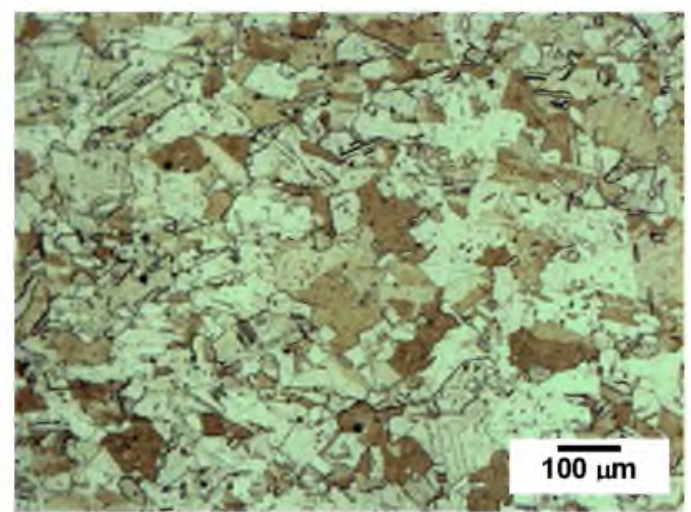

(d)

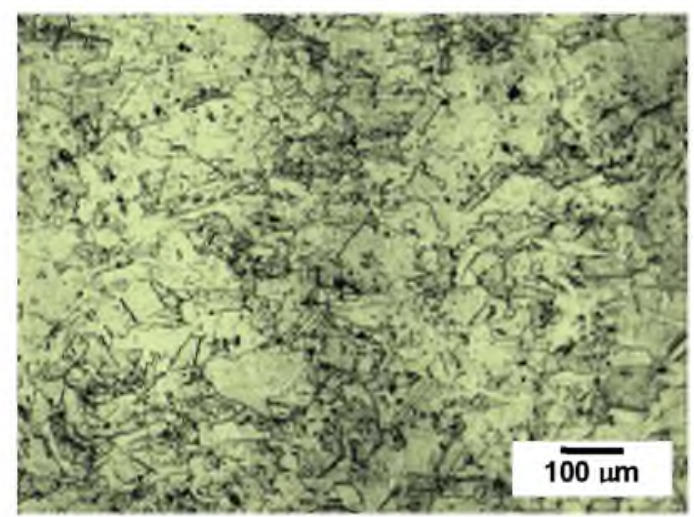

(c)

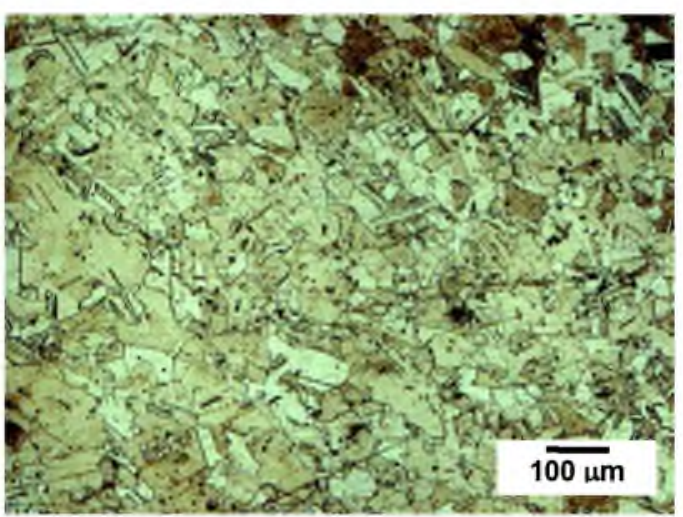

(e)

Figure 1 Optical micrographs showing the microstructures after SR and HIP processes: (a) asbuilt, (b) after SR-1, (c) after SR-2, (d) after SR-1+HIP, after SR-2+HIP 


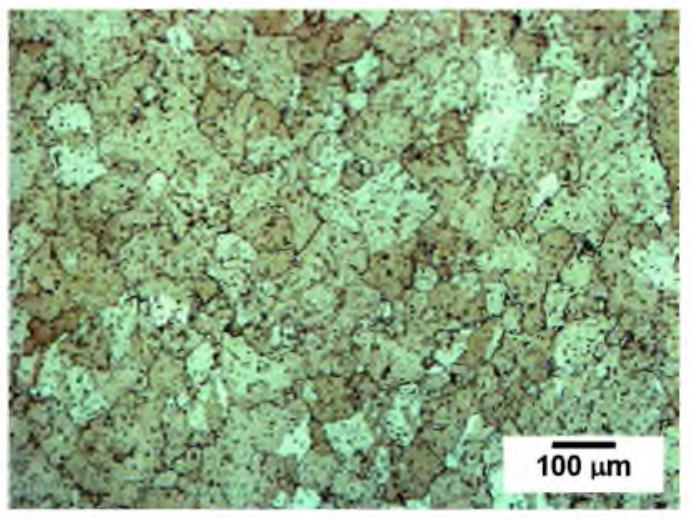

(a)

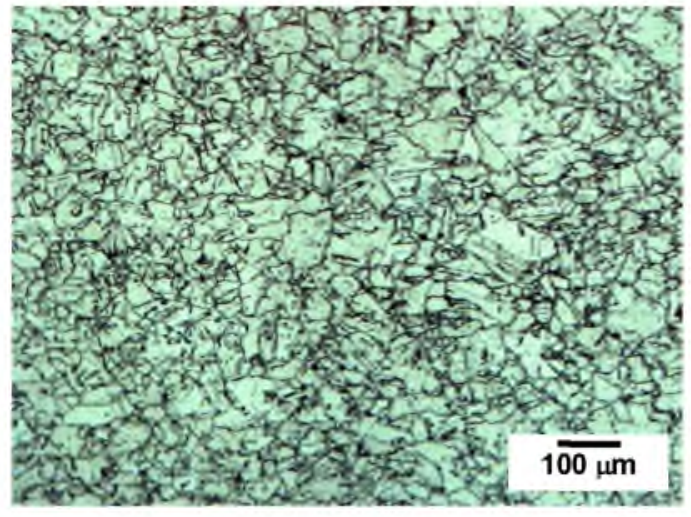

(b)

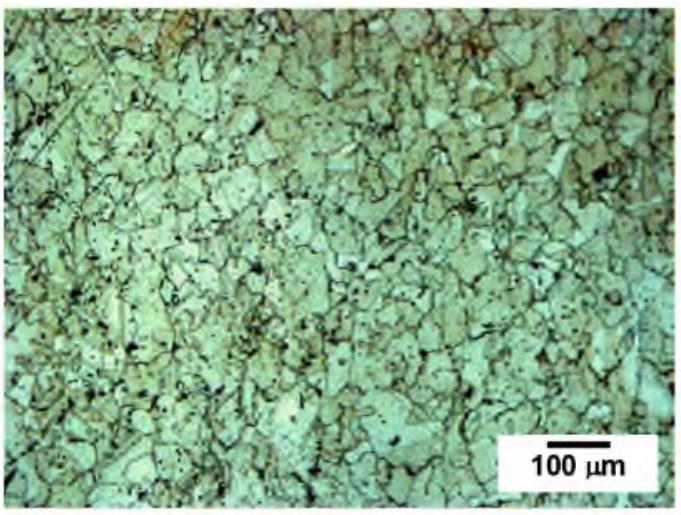

(c)

Figure 2 Optical micrographs showing the changes of aged microstructure in different heat treatment conditions: (a) after SR+HIP+AMS 5662, (b) after SR-1+HIP+HT-1, and (c) after SR-2+HIP+HT-2

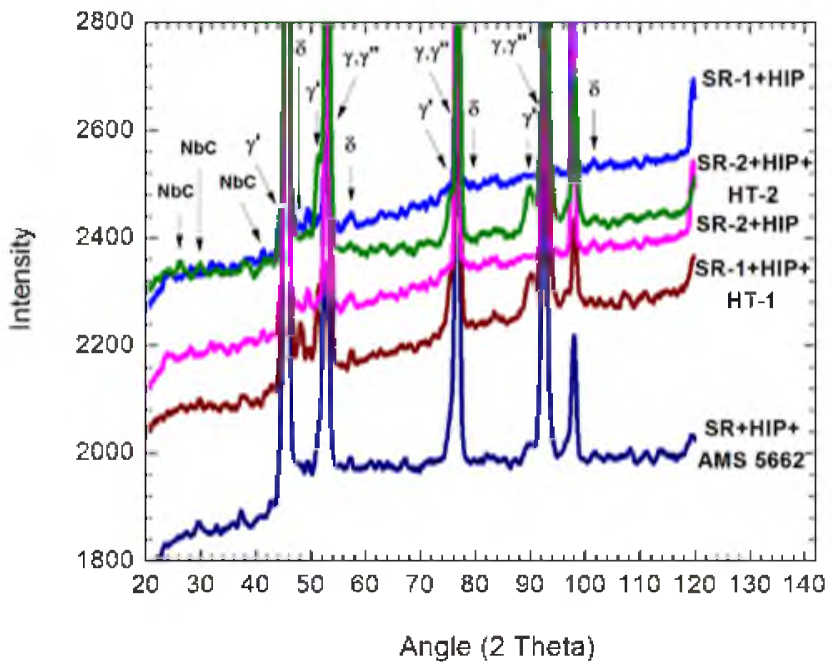

Figure 3 XRD patterns showing formation of the $\gamma^{\prime}, \gamma^{\prime \prime}, \delta$ and $\mathrm{NbC}$ precipitation phases in different heat treated microstructures 


\section{Evolution of $y^{\prime}, y^{\prime \prime}, \delta$ and Carbide Particles in the Aged Microstructures}

Alloy 718 is mainly strengthened by the metastable $\gamma^{\prime}$ and $\gamma^{\prime \prime}$ phases, but the dispersion of $\delta$ phase at grain boundaries can strengthen the grain boundaries by inhibiting the expansion of the grain boundaries and slipping of dislocations from one grain to the adjacent one. In order to have a better understanding of the carbides, $\gamma^{\prime}, \gamma^{\prime \prime}$ and $\delta$ precipitation phases with the size and volume fraction an SEM analysis was carried out.

SEM micrographs of the aged microstructures after SR-1+HIP+HT-1 and SR-2+HIP+HT-2 treatments are shown in Figures 4 and 5. The solution treatment at $950{ }^{\circ} \mathrm{C}$ for $1 \mathrm{~h}(\mathrm{HT}-1)$ resulted in the extensive precipitation of acicular $\delta$ phase at the grain boundaries (Figure 4a). The Ni and $\mathrm{Nb}$ elemental distribution analysis clearly shows how the $\delta$ phase distributed inside and along the grain boundaries (Figure 4b). The solution treatment in the temperature range $980{ }^{\circ} \mathrm{C}$ (AMS 5662) $-1035{ }^{\circ} \mathrm{C}$ (HT-2) brought excessive grain growth in spite of the $\delta$ phase not being fully dissolved (Figure 5a). The size and volume fraction of $\delta$ phase in the SR-2+HIP+HT-2 aged microstructure can be seen in Figure $5 \mathrm{~b}$. For full precipitation of $\gamma^{\prime} / \gamma^{\prime \prime}$, the precipitate constituents $\left(\mathrm{Nb}, \mathrm{Al}\right.$, and $\mathrm{Ti}$ ) must be dissolved in the matrix. Above $1032{ }^{\circ} \mathrm{C}$, some of the $\mathrm{NbC}$ carbides dissolve and provide more $\mathrm{Nb}$ for $\gamma^{\prime \prime}$ precipitation [14]. At $1035^{\circ} \mathrm{C}$, a high volume fraction of disc shape and globular morphologies $\gamma^{\prime}$ and $\gamma^{\prime \prime}$ was observed (Figure 5c).

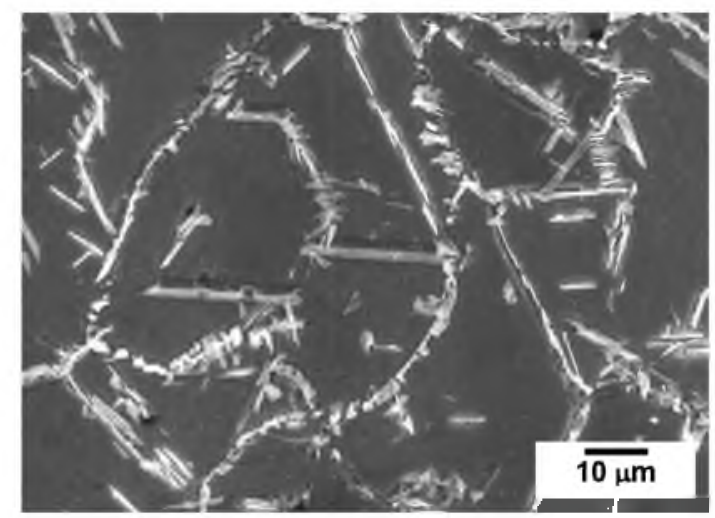

(a)
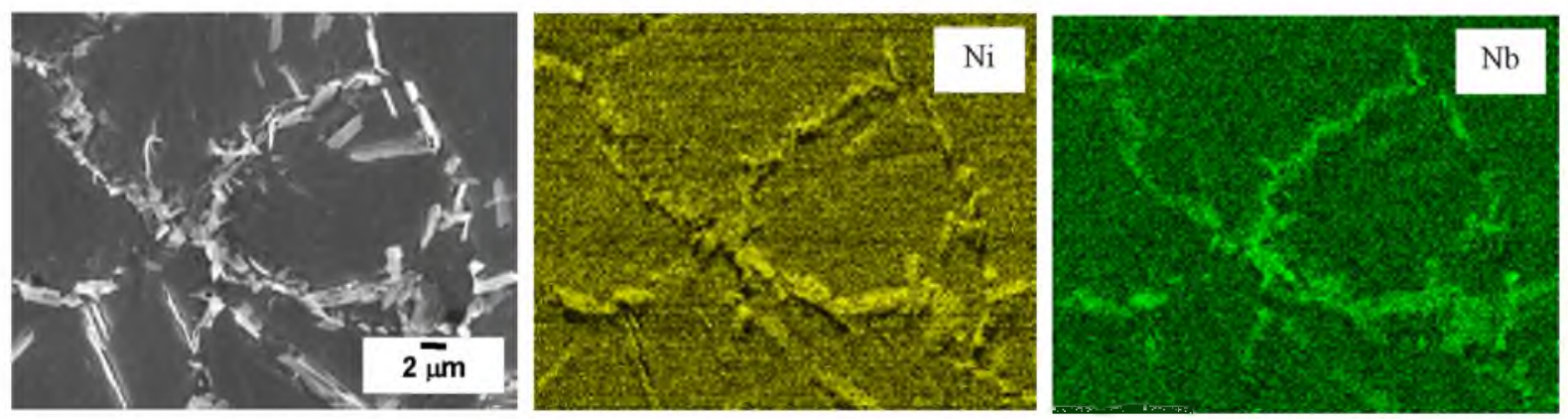

(b)

Figure 4 (a) SEM micrograph showing $\delta$ phase in SR-1+HIP+HT-1 aged microstructure, and (b) its $\mathrm{Ni}$ and $\mathrm{Nb}$ elements mapping 


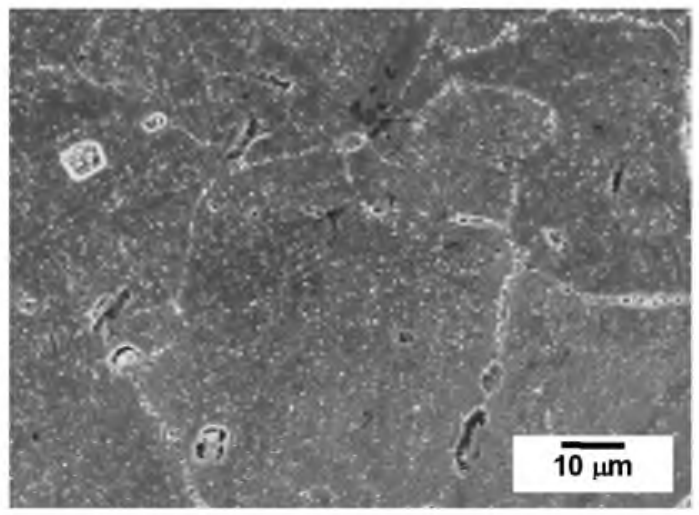

(a)

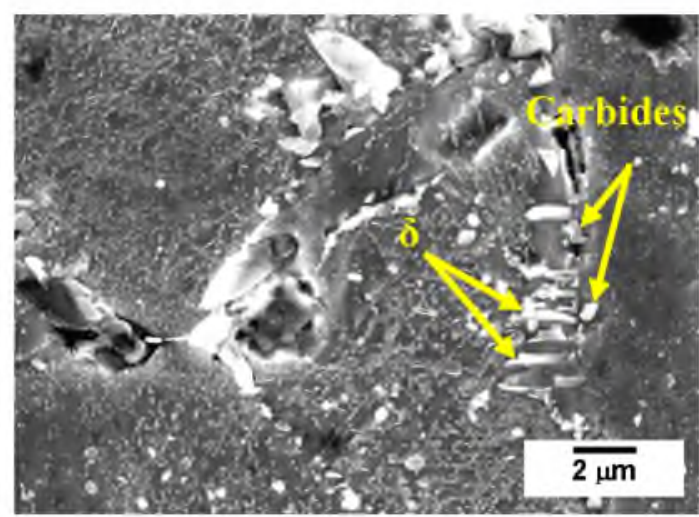

(b)

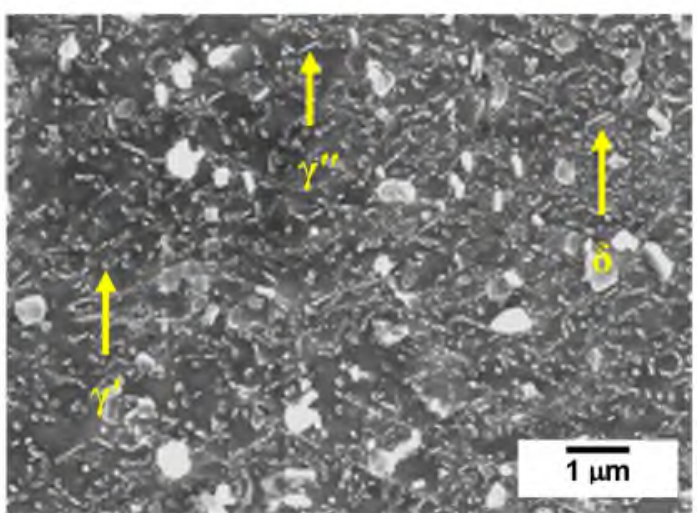

(c)

Figure 5 (a) SEM micrograph showing sizes and volume fractions of the precipitation phases in SR-2+HIP+HT-2 aged microstructure, (b) the carbides and $\delta$ phases at the grain boundary, and (c) $\delta, \gamma^{\prime}$ and $\gamma^{\prime \prime}$ phases inside the grain

The extensive precipitation of $\gamma^{\prime}$ and $\gamma^{\prime \prime}$ can result in a substantial improvement in hardness. The comparison between the microhardness values of different aged microstructures are shown in Figure 6 . The microhardness values of all aged microstructures were above the target hardness of solution heat treated and two-stage aged alloy 718 in the literature, $430 \mathrm{HV}$ [15]. In this case, the value of the SR-2+HIP+HT-2 aged microstructure had the highest value of $489 \mathrm{HV}$ compared with the SR-1+HIP+HT-1 and AMS 5662 aged microstructures. The grain size, $\delta$ and $\mathrm{NbC}$ carbides, $\gamma^{\prime \prime}-\gamma$ misfit, $\gamma^{\prime}-\gamma$ misfit, and stored energy (residual plastic work) are factors contributing to the hardness evolution [12]. For the SR-2+HIP+HT-2 aged microstructure, the increase in hardness can be related to two distinct factors: (i) higher $\gamma^{\prime}$ and $\gamma^{\prime \prime}$ volume fraction and (ii) presence of secondary carbides. 


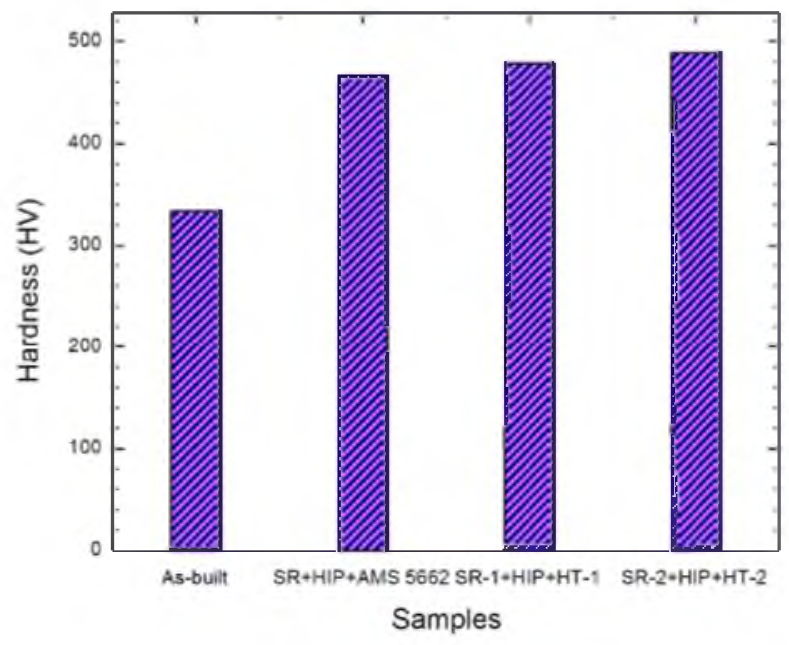

Figure 6 Comparison between the microhardness values of different aged microstructures

\section{Conclusions}

In this research, the relationships between heat treatment processes and the microstructural changes of 3D printed alloy 718 were studied. Several conclusions can be drawn as below:

- The columnar grains of the as-built sample can be completely substituted by heat treated equiaxed grains via stress relieving treatment of $1038^{\circ} \mathrm{C}$ for $1 \mathrm{~h}$.

- The solution treatment at $950{ }^{\circ} \mathrm{C} / 1 \mathrm{~h} /$ water quenching followed by two-stage ageing at 720 ${ }^{\circ} \mathrm{C} / 8 \mathrm{~h} /$ furnace cooling to $620^{\circ} \mathrm{C} / 8 \mathrm{~h} /$ air cooling to room temperature gave the significant grain refinement (average grain size-50 $\mu \mathrm{m}$ ) compared with the standard AMS 5662 (average grain size- $100 \mu \mathrm{m})$.

- The solution treatment at $1035^{\circ} \mathrm{C} / 1 \mathrm{~h}$ /water quenching followed by two-stage ageing at 720 ${ }^{\circ} \mathrm{C} / 10 \mathrm{~h} /$ furnace cooling to $620{ }^{\circ} \mathrm{C} / 10 \mathrm{~h} /$ air cooling to room temperature resulted in a higher microhardness value of $489 \mathrm{HV}$.

- Depending on the application and property requirement, the solution treatment temperature can be selected to alter the volume fraction of the $\delta$ phase to control the grain size. The holding time of two-stage ageing can be adjusted to achieve the high volume fraction of $\gamma^{\prime} / \gamma^{\prime \prime}$ strengthening phases in the aged alloy 718 . 


\section{References}

1. Z. Wang et al., "The Microstructure and Mechanical Properties of Deposited-IN718 by Selective Laser Melting," Journal of Alloys and Compounds, 513 (2012) 518-523.

2. T.J. Horn, and Ola L.A. Harrysson, "Overview of Current Additive Manufacturing Technologies and Selected Applications," Science Progress, 95 (2012) 255-282.

3. M. Vaezi, H. Seitz, and S.F. Yang, "A Review on 3D Micro-Additive Manufacturing Technologies," International Journal of Advanced Manufacturing Technology, 67 (2013) 17211754.

4. D. Manfredi et al., "Direct Metal Laser Sintering: an Additive Manufacturing Technology Ready to Produce Lightweight Structural Parts for Robotic Applications," METALLURGIA ITALIANA, 10 (2013) 15-24.

5. Q.B. Jia, and D.D. Gu, "Selective Laser Melting Additive Manufacturing of Inconel 718 Superalloy Parts: Densification, Microstructure and Properties," Journal of Alloys and Compounds, 585 (2014) 713-721.

6. G.A. Rao et al., "Effect of Standard Heat Treatment on the Microstructure and Mechanical Properties of Hot Isostatically Pressed Superalloy Inconel 718," Materials Science and Engineering A, 355 (2003) 114-125.

7. L. Chang et al., "Effect of Heat Treatment on Microstructure and Mechanical Properties of the Hot-isostatic-Pressed Inconel 718 Powder Compact," Journal of Alloys and Compounds, 590 (2014) 227-232.

8. S.X. Jin et al., "Evolution of Precipitate in Nickel-Base Alloy 718 Irradiated with Argon Ions at Elevated Temperature," Nuclear Instruments and Methods in Physics Research B, 307 (2013) $522-525$.

9. F.C. Liu et al., "Effect of Intermediate Heat Treatment Temperature on Microstructure and Notch Sensitivity of Laser Solid Formed Inconel 718 Superalloy," Journal of Wuhan University of Technology-Materials Science Edition, 26 (2011) 908-913.

10. S.H. Chang et al., "Influences of Soaking Time in Hot Isostatic Pressing on Strength of Inconel 718 Superalloy," Materials Transactions, 47 (2006) 426-432.

11. C.N. Wei, H.Y. Bor, and L. Chang, "Effect of Hot Isostatic Pressing on Microstructure and Mechanical Properties of CM-681LC Nickel-Base Superalloy Using Microcast," Materials Transactions, 49 (2008) 193-201.

12. A. Chamanfar et al., "Microstructural Characteristics of Forged and Heat Treated Inconel718 Disks." Materials and Design 52 (2013) 791-800.

13. M. Dehmas et al., "TEM Study of High-Temperature Precipitation of Delta Phase in Inconel 718 alloy." Advances in Materials Science and Engineering, 2011 (2011) 1-9.

14. C.M. Kuo et al., "Aging Effects on the Microstructure and Creep Behavior of Inconel 718 Superalloy." Materials Science and Engineering A, 510-511 (2009) 289-94.

15. M. Preuss, P.J. Withers and G.J. Baxter. "A Comparison of Inertia Friction Welds in Three Nickel Base Superalloys." Materials Science and Engineering A, 437 (2006) 38-45. 